\section{REFERENCES}

Altschuld, R. A., and Kruger, F. A. (1968). Annals of the New York Academy of Sciences, 148, 612 .

Christensen, N. J. (1967). Scandinavian Fournal of Clinical and Laboratory Investigation, 19, 379.

Fajans, S. S., Moorhouse, J. A., Doorenbos, H., Louis, L. H., and Conn, J. W. (1960). Diabetes, 9, 194.
Kreisberg, R. A. (1968). Annals of the New York Academy of Sciences, 148,743 .

Lundbæk, K. (1962). British Medical fournal, 1, 1507.

Madison, L. L., and Unger, R. H. (1960). Diabetes, 9, 202

Meyer, F., Ipaktchi, M., and Clauser, H. (1967). Nature, 213, 203.

Searle, G. L., Schilling, S., Porte, D., Barbaccia, J., De Grazia, J., and Cavalieri, R. R. (1966). Diabetes, 15, 173.

Williams, R. H., Tyberghein, J. M., Hyde, P. M., and Nielsen, R. L. (1957). Metabolism, 6, 311.

\title{
Erythema Nodosum due to Pasteurella pseudotuberculosis
}

\author{
D. S. WILKINSON,* M.D., F.R.C.P. ; T. W. TURNER, † M.B., B.S.; N. S. MAIR, F.C.PATH., D.P.H., DIPL.BACT.
}

Summary : Two children developed erythema nodosum $\checkmark$ due to Pasteurella pseudotuberculosis. Neither case showed typical signs of $\mathbf{P}$. pseudotuberculosis infection, but this cause was shown by positive agglutination tests. It is suggested that this organism is a more common cause of erythema nodosum than is at present recognized.

The purpose of this report is to draw attention to a cause of erythema nodosum in children and young adults which may easily escape notice. In recent years Pasteurella pseudotuberculosis infection has been recognized on the Continent, especially in France, as an underlying cause of erythema nodosum occurring either as a separate clinical entity or in association with mesenteric lymphadenitis (Evreux and Magard, 1967 ; Lèques and Verdaguer, 1967 ; Le Coulant et al., 1967). In this country Bouton and Hall diagnosed $P$. pseudotuberculosis infection in a 14-year-old girl admitted to Alder Hey Children's Hospital, Liverpool, with erythema nodosum and a four-month history of intermittent abdominal pain (cited by Mollaret, 1962).

In the following cases the patients did not show the abdominal symptoms characteristic of $P$. pseudotuberculosis infection. In one case the erythema nodosum followed a nonspecific febrile upper respiratory illness and in the other erythema nodosum was the only clinical manifestation.

\section{Case 1}

A girl of 6 years was referred by her general practitioner on account of erythema nodosum. Her mother stated that on 29 August 1968 she complained of loss of appetite and general malaise. By 1 September she had become febrile, her temperature reaching $39.5^{\circ} \mathrm{C}$. over the next three days. At that stage the family doctor noted numerous reddish blue lumps on toth shins and referred her to one of us (D. S. W.). Examination on 12 September showed a classical resolving erythema nodosum on both legs with typical bruised discoloration. Although the patient was afebrile and had no other complaints or abnormal physical signs, the mother stated that she had not yet recovered her normal health. During the succeeding 10 days complete recovery occurred.

Investigations.- $\mathrm{Hb} 80 \%$; W.B.C. $6,900 / \mathrm{cu} . \mathrm{mm}$. ; E.S.R. (Westergren) $74 \mathrm{~mm} . /$ hour; antistreptolysin-O titre, less than $200 \mathrm{u} . / \mathrm{ml}$. Chest x-ray examination showed no evidence of

\footnotetext{
- Consultant Dermatologist, Aylesbury and High Wycombe Hospital Groups.

† Dermatological Registrar, High Wycombe Hospital Group.

$\ddagger$ Director, Public Health Laboratory Service, Leicester.
}

tuberculosis or sarcoidosis. Tuberculin test negative at $1 / 1,000$ dilution. Brucella and salmonella agglutinins negative.

Serum taken from the patient on 12 September was found to agglutinate $P$. pseudotuberculosis (type $I$ ) to a titre of $1 / 1,280$. An intradermal test with $P$. pseudotuberculosis antigen produced a positive result (erythema $10 \mathrm{~mm}$., induration $5 \mathrm{~mm}$.) 24 hours after the injection. Serum taken from the patient three months later showed no agglutinins for $P$. pseudotuberculosis.

Serum specimens from five other members of the household were examined with negative results. At about the time the patient became ill the family had acquired a stray cat which was unwell and had sticky eyes. Blood was taken from the animal, but unfortunately an insufficient amount was obtained to allow the agglutination titre to be determined.

\section{Case 2}

A girl aged 15 had a history of recurrent "bilious" attacks, occurring at intervals of two to three months, over a period of two years. The attacks, which lasted one day, were characterized by vomiting and headache but no diarrhoea. One of these attacks (11 January 1969) coincided with the development of small, tender nodules on both legs and arms. There was no fever, and the patient remained well subjectively. Because of the persistence of the lesions she was seen by her general practitioner, who referred her to one of us (D.S.W.). On examination she showed typical resolving erythema nodosum on legs and arms, There was no lymphadenopathy.

Investigations.-Hb $100 \%$; W.B.C. 7,800/cu.mm. ; E.S.R. 37 $\mathrm{mm}$./hour; antistreptolysin-O titre, less than $200 \mathrm{u} . / \mathrm{ml}$. Chest $x$-ray examination showed no evidence of tuberculosis or sarcoidosis. Tuberculin test negative at $1 / 1,000$ dilution. Intradermal test with $P$. pseudotuberculosis antigen produced a pronounced reaction (induration $10 \mathrm{~mm}$., erythema $20 \mathrm{~mm}$.) at 48 hours.

Serum taken on 19 January agglutinated $P$. pseudotuberculosis type IV to a titre of $1 / 1,280$ and Salmonella typhi $O$ to a titre of $1 / 160$. Tests for other salmonella agglutinins were negative. The specificity of the agglutination test for $P$. pseudotuberculosis type IV is affected by the antigenic relationship which exists between type IV and O factor 9 of the salmonella D group to which $S$. typhi belongs. In order that a serological diagnosis can be made it is necessary to absorb the patient's serum with a strain of the $D$ group. In the present case the patient's serum was absorbed with a strain of $S$. typhi. After absorption agglutinins to type IV were still present at a titre of $1 / 640$, indicating infection with $P$. pseudotuberculosis.

\section{Comment}

Many different agents have been incriminated as causes of erythema nodosum. In recent years tuberculosis has become 
an uncommon cause, even in childhood. Sarcoidosis is a frequent cause in young adults but not in children. Drugs, fungal infections, and rickettsial and cat-scratch fever can evoke this reaction on occasion, but cases in children are often too readily attributed to a streptococcal infection if they follow a febrile upper respiratory illness.

Infection with $P$. pseudotuberculosis is not infrequent in this country. Mair (1968b) recorded 96 cases of the infection over a seven-year period, and Hall (1967, personal communication) observed 26 cases among children admitted to Alder Hey Children's Hospital between January 1960 and November 1961. A fatal case presenting as a "septicaemic" form of the disease was reported by Macaulay et al. (1967). The organism has been found in a wide variety of wild and domestic animals in the United Kingdom (Mair, 1968a). It is probable that human infection arises from the ingestion of foodstuffs contaminated with animal excretions.

In France Mollaret (1968), investigating 130 cases of erythema nodosum in whom the usual causes had been eliminated, found evidence, of $P$. pseudotuberculosis infection in 55 cases ( 32 associated with mesenteric lymphadenitis and 23 occurring as separate clinical entities). According to Mollaret erythema nodosum occurs in about $10 \%$ of patients with pseudotuberculous mesenteric lymphadenitis. The presence of widespread unrecognized infection with the organism is suggested by the work of Evreux and Magard (1967). These workers, in a series of intradermal tests on French children without a suggestive history of $P$. pseudotuberculosis infection, showed a steady rise in the incidence of positive reactors from $0 \%$ below 9 years to $14 \%$ at ages 10 to 13 and $38 \%$ at 14 to 17 years. There is no reason to believe that latent pseudotuberculosis is confined to France in view of the widespread presence of the organism in the fauna of the United Kingdom. Our patients might not have been diagnosed had they not been referred in the course of a survey of erythema nodosum being undertaken in Buckinghamshire under the aegis of the Chiltern Medical Society. Similar cases with a relatively benign illness would normally be treated at home and probably regarded as streptococcal in nature.

\section{REFERENCES}

Evreux, R., and Magard, H. (1967). Revue Médicale Normande, 9, 229. Le Coulant, R., Texier, L., and Géniaux, M. (1967). Bulletin de la Société Française de Dermatologie et de Syphiligraphie, 74, 501.

Lèques, B., and Verdaguer, S. (1967). Bulletin de la Société Française de Dermatologie et de Syphiligraphie, 74, 149.

Macaulay, J. D., Wilson, J. A. C., Abbott, J. D., and Mair, N. S. (1967). British Medical fournal, 2, 553.

Mair, N. S. (1968a). In Some Diseases of Animals Communicable to Man in Britain, Proceedings of a Symposium, London, 1966, edited by O. Graham-Jones. Oxford and New York, Pergamon Press.

Mair, N. S. (1968b). In Proceedings of the International Symposium on Pseudotuberculosis, Paris, 1967. Basle, Karger.

Mollaret, H. H. (1962). Presse médicale, 70, 1923.

Mollaret, H. H. (1968). In Proceedings of the International Symposium on Pseudotuberculosis, Paris, 1967. Basle, Karger.

\section{Preliminary Communications}

\section{Stress Effect of Antilymphocyte Serum}

British Medical fournal, 1969, 2, 227-229

\begin{abstract}
Cummary : Antilymphocyte serum prepared in the rabbit against guinea-pig lymph node cells produces a sustained weight loss when injected into normal guinea-pigs over 14 days, compared with a very transient loss produced by normal rabbit serum. Antilymphocyte serum also produces a much greater increase in plasma cortisol level than normal rabbit serum. Part of this effect may be due to adrenal stimulation, and further studies of its activity in adrenalectomized animals are suggested.
\end{abstract}

\section{INTRODUCTION}

Antilymphocyte serum has a well-marked suppressive effect on cell mediated (delayed) hypersensitivity reactions (Ciba Foundation, 1967). Nevertheless, it also induces a considerable reaction at the injection site, so instituting a stress reaction. Although there are many theories of the mode of action of antilymphocyte serum, few have sought to evaluate what part release of corticosteroids into the blood may play, and at a recent symposium (Ciba Foundation, 1967) it was not mentioned at all. It has, however, been considered briefly by Woodruff et al. (1951), Woodruff $(1960,1967)$, and also by Gray et al. (1966). The present work studies blood cortisol levels in guinea-pigs inoculated with antilymphocyte serum made in the rabbit.

\section{Materials AND METHODS}

Normal Hartley or strain-13 guinea-pigs (400-500 g.) were used for this work and maintained on sow cube diet with water ad libitum. Animals of both sexes were used, but within a given experiment all were of one sex.

Blood cortisol levels were estimated from specimens $(0.5 \mathrm{ml}$.) withdrawn by cardiac puncture under light ether anaesthesia by the method of Mattingly (1962) adapted for use on a semimicroscale, $1.5 \mathrm{ml}$. of dichloromethane F.D.P.C. being added to $0.2 \mathrm{ml}$. of the heparinized plasma in a 3-ml. tube with a ground-glass stopper. Blanks (distilled water) and standards (100 $\mu \mathrm{g}$. of cortisol per $100 \mathrm{ml}$. of distilled water) were processed at the same time. Full procedural details are to be published (Cook).

Under the conditions of the test, blanks gave a fluorescent reading of about 9 and the standard about 65, so that some 55 scale divisions represented a range of $0-100 \mu \mathrm{g}$. of cortisol per $100 \mathrm{ml}$. of plasma and readings could easily be taken to half a division.

Since many of the guinea-pig estimations proved to be much higher than those customarily dealt with in human subjects, it was possible to make measurements with as little as 0.1 or $0.5 \mathrm{ml}$. of plasma if necessary.

Antilymphocyte serum was prepared by inoculation of fine suspensions of Hartley guinea-pig cervical and mesenteric lymph node cells intravenously into rabbits. Each inoculation consisted of about $10^{8}$ cells (of which about half were viable as shown by a trypan blue exclusion test). These inoculations were repeated at intervals of two to three weeks, and 10 days after the second injection the serum was found to be highly potent in preventing experimental allergic encephalomyelitis (unpublished work).

Three experiments were concerned with blood cortisol levels four hours after inoculation of antilymphocyte serum $(1 \mathrm{ml}$. intraperitoneally $+1 \mathrm{ml}$. intramuscularly in a fore limb), and 